\title{
THE EFFECT OF R-FACTOR CARRIAGE ON THE SURVIVAL OF ESCHERICHIA COLI IN THE HUMAN INTESTINE
}

\author{
J. D. ANDERSON
}

Department of Bacteriology, The Medical School, University Walk, Bristol BS8 ITD

THE introduction of most antibiotics has been initially followed by reports of a progressively increasing population of resistant organisms (Finland, 1972). Since the discovery of antibiotic-resistance transfer (R) factors (Watanabe, 1963) a high proportion of antibiotic resistance in the Enterobacteriaceae and pseudomonads has been shown to be mediated by these plasmids. However, the fear that all organisms capable of R-factor transfer might become solidly resistant to all antibiotics has not been realised. Indeed, recent evidence suggests that the incidence of antibiotic-resistant organisms may have levelled off, or even fallen, for at least some organisms in some human populations (Slocombe and Sutherland, 1969; Price and Sleigh, 1970; Gillespie et al., 1971; Lowbury, Babb and Roe, 1972). This change may have resulted from a more responsible use of antibiotics in human and veterinary practice, and suggests that bacteria bearing $\mathrm{R}$ factors are at an ecological disadvantage in nature in the absence of selection pressure from antibiotics.

Preliminary experiments showed that, in general, organisms bearing $R$ factors died more rapidly on storage in saline or water (Anderson, 1973) and failed to grow as quickly in broth as corresponding R-factor-free organisms. However, it is doubtful that results obtained in the laboratory are applicable in nature where bacteria grow under quite different conditions. The human gastrointestinal tract is of particular interest as a site for study of the survival and colonisation of R-factor-bearing organisms under natural conditions because it contains a captive population of various organisms that might be involved in R-factor transfer, some of which are of obvious clinical interest. The limitations of in-vitro studies in predicting events in vivo have been clearly shown for the human gastro-intestinal tract, where detectable R-factor transfer could not be demonstrated in four persons, in the absence of antibiotics, even though the donor and recipient organism were present in the faeces in numbers at which $\mathrm{R}$-factor transfer would have occurred freely had the organisms been in broth (Anderson, Gillespie and Richmond, 1973a).

In the present study, organisms were genetically marked by chromosomally determined antibiotic-resistant mutants. Some of these marked organisms were also rendered resistant to other antibiotics by introduction of an $\mathrm{R}$ factor. $\mathrm{R}$-factor-bearing and R-factor-free strains were then ingested on the same day by healthy persons. Studies of the faecal flora over the next 7 days showed that, in general, R-factor-bearing organisms disappeared from the faeces more rapidly than the control organisms. 


\section{MATERIALS AND METHODS}

Media. MacConkey bile-lactose agar was prepared with and without antibiotics as previously described (Anderson et al., 1973).

Antibiotic-sensitivity tests by the filter-paper-disk technique were performed on Oxoid DST Agar (Oxoid Ltd, London S.E.1) supplemented with saponin-lysed oxalated horseblood.

Preparation of organisms. Five organisms were isolated from the faeces of four individuals and were shown by biochemical (Cowan and Steel, 1965) and antibiotic-sensitivity tests to be fully sensitive strains of Escherichia coli. Chromosomally marked mutants of the selected organisms were prepared; these were resistant to either rifampicin or nalidixic acid, and $\mathrm{R}$ factors were introduced into some of these marked organisms as previously described (Anderson et al., 1973a). Two of the individuals (table, subjects 1 and 4) who provided organisms participated in the present study and ingested organisms derived from strains isolated from their own faeces.

Two F-like $f^{+}$repressed $\mathrm{R}$ factors, in strains of $E$. coli given by Dr N. Datta, Royal Postgraduate Medical School, London, were used in this work because their molecular characteristics and behaviour in the gastro-intestinal tract in the presence and absence of antibiotics have already been studied in this department (Anderson, et al., 1973a; Anderson et al., 1973b). The plasmid R-1 conferred resistance to ampicillin, chloramphenicol, kanamycin, streptomycin, and sulphonamides. The plasmid R-222-1 conferred resistance to chloramphenicol, streptomycin, sulphonamides, and tetracyclines.

Experimental subjects. All but one of the healthy volunteers participating in these experiments were bacteriologists employed by the University of Bristol or the United Bristol Hospitals. Nine men and three women took part in 14 experiments. To determine the nature of the resident faecal aerobic Gram-negative flora in each person, samples of faeces were obtained on two to four occasions during the week before the test organisms were ingested.

Ingestion of bacteria. Stationary-phase organisms from an overnight broth-culture were concentrated by centrifugation and the cell slurry, containing $10^{10}-10^{11}$ viable organisms, was transferred to a gelatin capsule for ingestion with milk or orange juice. Each capsule was given at a separate time to eliminate the remote possibility of $\mathrm{R}$-factor transfer occurring in the mouth. In half of the experiments a chromosomally labelled tracer organism was given in mid-morning and an approximately equal number of R-factor-bearing organisms in mid-afternoon. This order of ingestion was reversed in the remaining experiments.

Investigation of faecal flora. Specimens of faeces were usually studied within 3 hours of voiding by methods already described in full (Anderson et al., 1973a). In outline: viable counts of antibiotic-sensitive and -resistant Gram-negative aerobic faecal bacteria were determined on MacConkey agar with and without antibiotics. About 10 lactose-fermenting organisms were picked from each antibiotic plate and the sensitivity pattern studied further by the filter-paper disk technique on lysed-blood agar plates. The identity of a random selection of antibiotic-resistant isolates of $E$. coli was confirmed biochemically.

\section{RESULTS AND DISCUSSION}

Preliminary laboratory experiments showed that the chromosomally " marked" mutants of $E$. coli that were resistant to rifampicin and nalidixic acid failed to survive as well as their antibiotic-sensitive progenitors in broth and in distilled water and grew more slowly in broth at $37^{\circ} \mathrm{C}$. Chromosomally marked organisms were therefore employed as "controls" in these experiments in preference to fully antibiotic-sensitive organisms.

The table lists the various combinations of chromosomally marked organisms, with or without $\mathrm{R}$ factors, that were ingested by the 12 subjects. Changes in the ratio between the number of $\mathrm{R}$-factor-bearing to $\mathrm{R}$-factor-free 
R-FACTOR AND SURVIVAL OF E. COLI

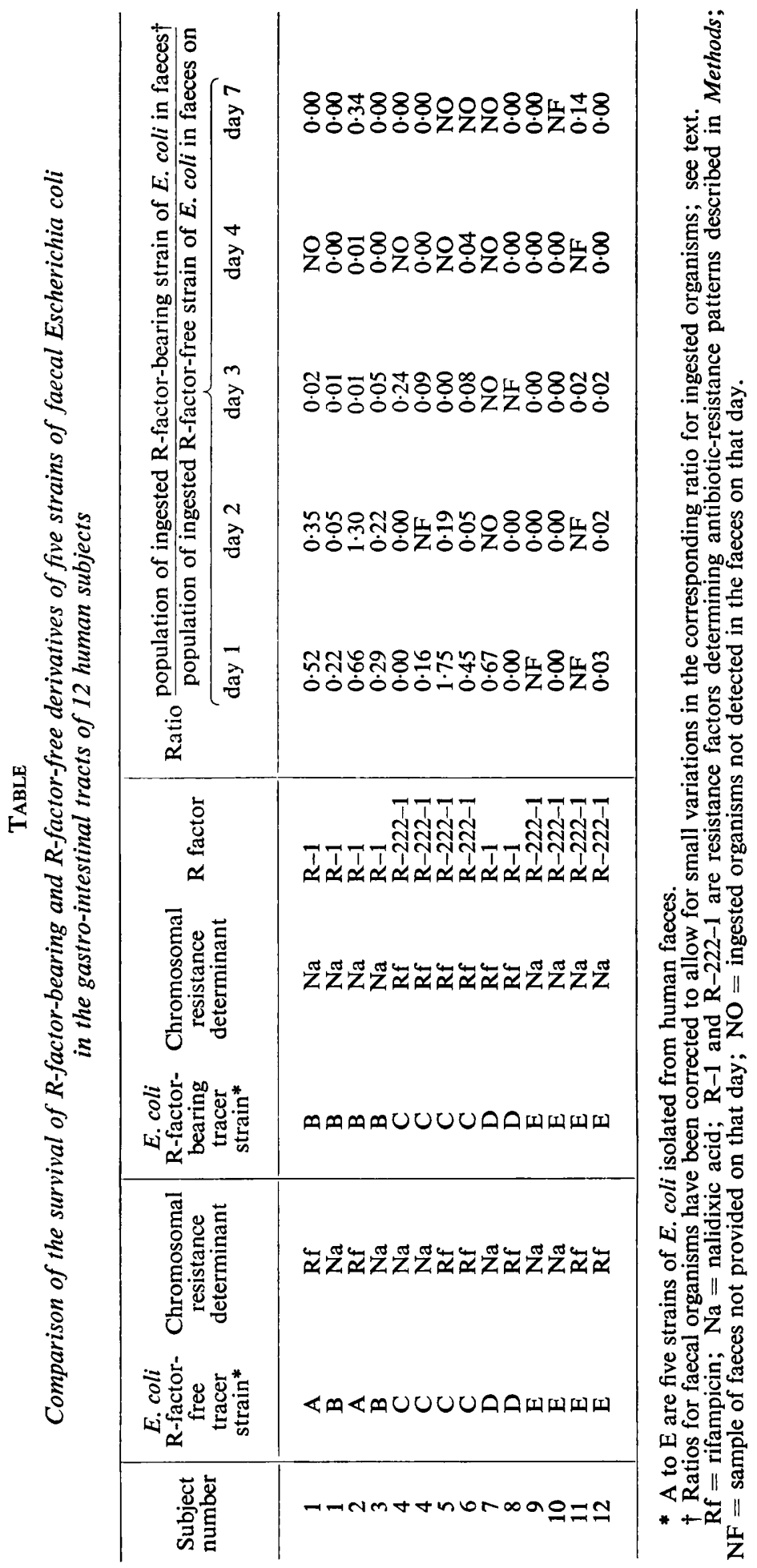


ingested organisms in the faeces provided a measure of the survival of these plasmids in vivo relative to the control organisms. Because, for ingested organisms, this ratio differed slightly from unity (mean value 1.00 to $1 \cdot 14$ ), the ratios shown for faecal organisms in the table have been individually corrected to a nominal initial ratio of 1 to 1 . Altogether 54 samples of faeces were examined during the week after ingestion of the bacteria. In 52 samples the R-factorbearing organisms were isolated in relatively smaller numbers than the controls. In the other two samples the reverse phenomenon was observed but the effect was not marked. The mean population of organisms with determinants of the ingested $\mathrm{R}$ factors fell from $11.8 \%$ of the total faecal aerobic Gram-negative bacteria on day 1 to $0.08 \%$ on day 7 . The decay rate was approximately logarithmic.

An incidental finding in one experiment was the isolation of strains of $E$. coli with resistance determinants consistent with plasmid transfer from an ingested donor with antibiotic determinants for nalidixic acid and R-222-1 to a recipient resistant to rifampicin. These organisms formed only $0.05-0.5 \%$ of the total number of organisms with the grouped antibiotic-resistance determinants of R-222-1 and were therefore ignored for the purposes of this study.

The rapid disappearance of $\mathrm{R}$-factor-bearing ingested organisms from the faeces relative to the controls may have been a result of spontaneous loss or fragmentation of the plasmids or from inpairment of the growth rate or vitality of the organism. Chromosomally labelled organisms with resistance determinants compatible with loss or fragmentation of the $\mathrm{R}$ factors used in these experiments were not isolated in any experiment. In a similar experiment in which chromosomally marked organisms bearing these same two plasmids were each ingested by two people, there was no evidence of loss or fragmentation of resistance determinants in 276 chromosomally marked organisms that were isolated from the faeces (Anderson et al., 1973a). The reduced virulence of some R-factor-bearing enteric pathogens in experimental infections (Jarolmen and Kemp, 1969; Thiele, 1970; Smith, 1972) also indicates that plasmid carriage impairs bacterial function. The available evidence therefore strongly suggests that the fall in the population of $\mathrm{R}$ factors in the gut in these experiments was largely if not entirely due to an ecological disadvantage conferred on the bacterium rather than by plasmid loss from the cell. However, because loss or fragmentation of $\mathrm{R}$ factors has been demonstrated in broth either on serial sub-culture (Smith and Hallas, 1966), or on exposure to certain antihelminthic agents (Walton, 1972), it may be another factor in reducing the number of antibiotic-resistant strains in other populations.

Most $\mathrm{R}$ factors contain enough DNA to specify at least 50 gene products (Clowes, 1972), and different plasmids may determine the same resistance pattern with a variety of enzymes (Richmond and Sykes, 1973). One of the main problems in epidemiological work with $\mathrm{R}$ factors is to ascertain whether plasmids with the same resistance pattern in ingested and faecal organisms are in fact identical or whether the observed resistance pattern is coincidental. A study of only four or five resistance determinants is therefore not normally a sufficiently precise method of identifying a plasmid. However, in the present 
series of experiments the subjects were not exposed to antibiotics that might have selected multi-resistant organisms. Furthermore, before ingestion of the experimental plasmids, coliforms with more than three of the determinants of the ingested plasmids were not isolated from the faeces and none was resistant to chloramphenicol, an antibiotic determinant of both experimental plasmids. Similarly, detection of chromosomal markers conferring resistance to nalidixic acid and rifampicin was sufficient to identify strains of $E$. coli because organisms resistant to either of these antibiotics were not detected in the faeces of any of the subjects before administration of the test organisms. It may be concluded, therefore, that the techniques used to identify plasmids and organisms were sufficient for the limited aims of these experiments.

\section{SUMMARY}

The survival of " marked" strains of Escherichia coli bearing antibioticresistance-transfer ( $R$ ) factors was studied in the faeces of healthy human volunteers for 7 days after ingestion. Two $\mathrm{R}$ factors, determining resistance to ampicillin/chloramphenicol/kanamycin/streptomycin/sulphonamides and to chloramphenicol/streptomycin/sulphonamides/tetracyclines were used in 14 experiments on 12 persons. Strains without $\mathrm{R}$ factors served as controls. Both $\mathrm{R}$-factor-bearing and R-factor-free strains were identified by chromosomally determined resistance markers.

The R-factor-bearing organisms were isolated from the faeces in fewer numbers than the controls in 52 out of the 54 samples studied. In the two samples in which the reverse phenomenon was observed the effect was not marked. The fall in the number of R-factor-bearing organisms was generally progressive, and 4 days after ingestion the mean faecal population of $\mathrm{R}$-factorbearing organisms was only $0.5 \%$ of the control organisms. The relative decline in the R-factor population probably resulted from impaired vitality of organisms bearing these plasmids rather than from loss of $\mathrm{R}$ factors from the cell.

I am grateful to Professors W. A. Gillespie and M. H. Richmond for their interest and advice and to Mrs H. M. Clements for her technical help.

This work was supported by a Programme Grant for Molecular and Epidemiological Studies on R factors and other Plasmids from the Medical Research Council to M. H. R.

\section{REFERENCES}

ANDERSON, J. D. 1973. The effect of resistance-transfer (R) factor carriage upon the survival of Escherichia coli in vitro and experimentally in man. J. med. Microbiol., 6, xix.

Anderson, J. D., Gillespie, W. A. AND Richmond, M. H. 1973a. Chemotherapy and antibiotic resistance transfer between Enterobacteria in the human gastro-intestinal tract. J. med. Microbiol., 6, 461.

Anderson, J. D., Ingram, L. C., Richmond, M. H. ANd Wiedemann, B. 1973b. Studies on the nature of plasmids arising from conjugation in the human gastro-intestinal tract. J. med. Microbiol., 6, 475.

Clowes, R. C. 1972. Molecular structure of bacterial plasmids. Bact. Rev., 36, 361.

Cowan, S. T. AND SteEl, K. J. 1965. Manual for the identification of medical bacteria. London. 
FinLAND, M. 1972. Changing patterns of susceptibility of common bacterial pathogens to antimicrobial agents. Ann. intern. Med., 76, 1009.

Gillespie, W. A., Lee, P. A., Linton, K. B. AND Rowland, A. J. 1971. Antibiotic resistance of coliform bacilli in urinary infection acquired by women outside hospital. Lancet, 2, 675.

JAROLMEN, H. AND KemP, G. 1969. R-factor transfer in vivo. J. Bact., 99, 487.

Lowbury, E. J. L., BABB, J. R. AND RoE, E. 1972. Clearance from hospital of Gram negative bacilli that transfer carbenicillin resistance to Pseudomonas aeruginosa. Lancet, $2,941$.

Price, D. J. AND Sleigh, J. D. 1970. Control of infection due to Klebsiella aerogenes in a neurosurgical unit by withdrawal of all antibiotics. Lancet, 2, 1213.

RICHMOND, M. H. AND SYKES, R. B. 1973. The $\beta$-lactamases of Gram-negative bacteria and their possible physiological role. Adv. microb. Physiol., 9, edited by A. H. Rose, and D. W. Tempest, London \& New York, p. 31.

SLOCOMBe, B. AND SUTHERLAND, R. 1969. Sensitivity of Gram-negative bacilli to ampicillin after six years clinical use. J. clin. Path., 22, 644.

Smith, H. W. 1972. The effect on virulence of transferring $\mathrm{R}$ factors to Salmonella typhimurium in vivo. J. med. Microbiol., 5, 451.

Smith, H. W. and Halls, S. 1966. Observations on infective drug resistance in Britain. Br. med. J., 1, 266.

Thiele, E. H. 1970. Virulence of R-factor-bearing Salmonella typhimurium. Infect. Immun., $2,516$.

WALTON, J. R. 1972. Loss of antibiotic resistance from bacteria exposed to anthelmintic agents. Vet. Rec., 91, 629.

WATANABE, T. 1963. Infective heredity of multiple drug resistance in bacteria. Bact. Rev., 27, 87. 